\title{
Observation Regarding Hoof Blocks Use In Dairy Cows
}

Teodor Florian STROE*, Aurel MUSTE, Florin BETEG, Ioana DÎRLEA, Loredana HODIŞ and Reka VARGA Departament of Surgery. University of Agricultural Science and Veterinary Medicine Cluj-Napoca, Faculty of veterinary Medicine, 3-5 Manastur Street, 400372, Cluj-Napoca, Romania. Corresponding author: stroeteodorflorian@yahoo.com

Bulletin UASVM Veterinary Medicine 72(1) / 2015,

Print ISSN 1843-5270; Electronic ISSN 1843-5378

DOI:10.15835/buasvmcn-vm: 10961

\begin{abstract}
Hoof health, detection and treatment of lameness are major challenges for veterinarians due to the high incidence in the herd and major economical loss. Early detection and treatment minimizes the losses, due to treatment costs and decrease of milk quantity.

The research tried to elaborate a therapeutic protocol which minimizes the pain, and diminishes the recovery period by applying hoof blocks in lame cows.

The study was performed on 180 dairy Holstein cows (at "Action Felix" Dairy farm) in Oradea, from June 2012 to June 2013, using two types of blocks: foam (Walkease) and wooden (BoviBond). The cows were divided in three lots.

If the claw needs longer time for healing, the affected claw can be elevated by applying a foam hoof or wooden block to relieve the weight bearing from the affected claw. Resting the affected hoof is highly efficient to promote healing and pain relief. This encourages the cow to move around, to feed as the pain is relieved.

The hoof blocks allows the cow to walk around freely, as the foam or wooden block wears down, the hoof disease is given time to heal. During a period of time, the blocks will worn down completely and the disease will be healed.
\end{abstract}

Keywords: claw, hoof, lameness, trimming.

\section{INTRODUCTION}

Hoof health, detection and treatment of lameness are major challenges for veterinarians due to the high incidence in the herd and major economic loss. Early detection and treatment minimizes the losses, due to treatment costs and decrease of milk quantity.

Most lameness in dairy cows is related to lesions of the claws. Treatment of a claw always starts with curative or corrective trimming with trimming discs or sharp trimming knives are essential for this job (Beteg et al., 2010). Overgrowth should be removed, bearing surfaces should be flat to preserve outer weight bearing, and loose horn should be removed.

Sogstad et al. (2005) showed that $41 \%$ of the cows housed in tie-stalls and $64 \%$ of the cows housed in freestalls had at least one disease in the hind hooves. Total costs of a single case of lameness are considerably greater than the treatment costs alone because lameness may reduce milk yield (Warnick et al., 2001), female fertility (Hernandez et al., 2001) and hasten culling (Booth et al., 2004).

The research tried to elaborate a therapeutic protocol which minimizes the pain, and diminishes the recovery period by applying hoof blocks in lame cows.

\section{MATERIALS AND METHODS}

The study was conducted on 180 dairy Holstein cows (at "Action Felix" farm) in Oradea, from June 2012 to June 2013, using two types of blocks: foam (Walkease) (Fig.1) and wooden (BoviBond) (Fig.2). 
In order to achieve the aims, the 180 dairy cows were subjected to general clinical examination. Based on hoof injuries, animals with lesions and lamemess was selected for trimming (just functional or corrective) and devided in three lots. The cows with hoof injuries and with lameness presented an prolonged rest time, spending less time for feeding, and as a consequence were registered milk drop and economical loses.

The cows with claw lesions were subjected to corrective and therapeutic trimming. For this they were restrained in lateral decubitus using a chute. The cows were divided in three lots, first lot of 6 cows treated with wooden blocks (severe lesions), second lot of 7 cows with foam blocks (mild lesions) and third lot of 30 cows (incipient lesions) just local treatment and waterproof bandage.

Claw trimming was performed in 5 steps or The Dutch Method, first 3 steps are functional the last 2 are curative (Raven et al., 1989).

1. Make the medial claw $7,5 \mathrm{~cm}$ long from the start of the hard horn (distal to periopla) to the toe using pincers. This is a crucial step due to the risk of cutting too much, if the toe is cut to short the corium is exposed to trauma, it is better to cut slightly too long then to short.

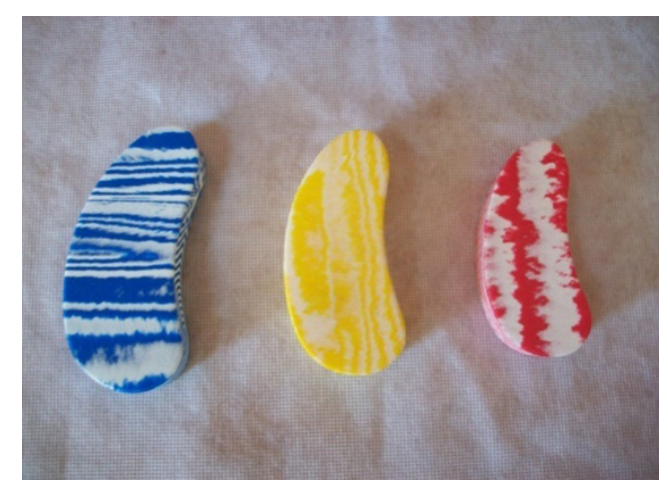

Fig. 1. Foam Blocks.

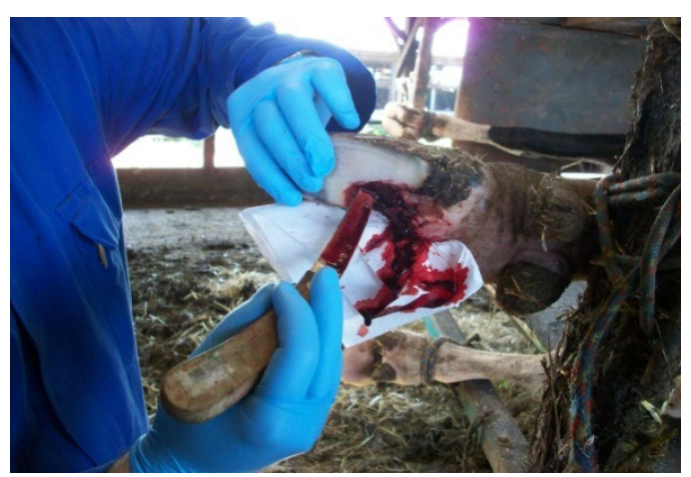

Fig. 3. Surgical debridement.
The heel must be protected as much as possible, in many cases is not needed to be trimmed, leave ample sole, $5-7 \mathrm{~mm}$. The weight bearing surface should be flat.

2. Using the inner claw make the lateral claw equally long and the bearing surface equally high.

3. Using hoof knives make a slope in the soles, do not reduce the weight bearing surface more than is necessary.

4. If one of the claws is diseased, lower this claw towards the heel $2 / 3$ of the sole, this way the weight bearing will be partially transferred to the sound claw if this is not enough it will be necessary to apply an orthopedic block on the sound claw.

Before applying the blocks surgical debridement of the nonviable tissue was performed using hoof knives, scalpels until healthy tissue appears (Fig.3). After debridement topical medication was applied (powders and sprays with antibiotics, iodoform ether) (Fig.4), and a waterproof bandage was applied (Fig.5).

Because the blocks come in different sizes is need to adjust the block to the sole of the sound claw(Fig.6), after this on the surface of the block was applied adhesive, the block was attached on the claw by applying pressure on it for 10-20

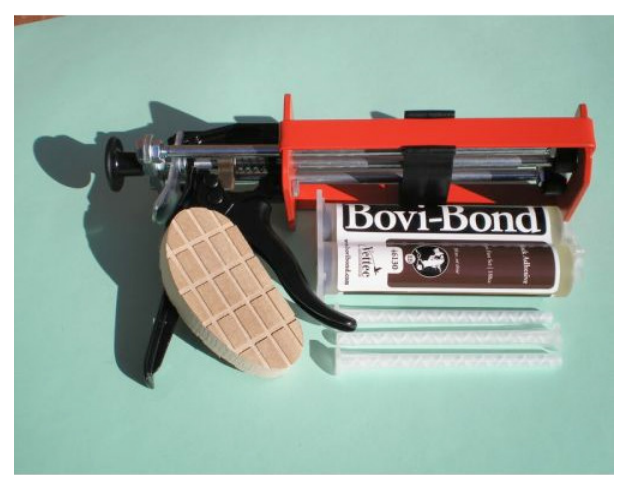

Fig. 2. Wooden blocks.

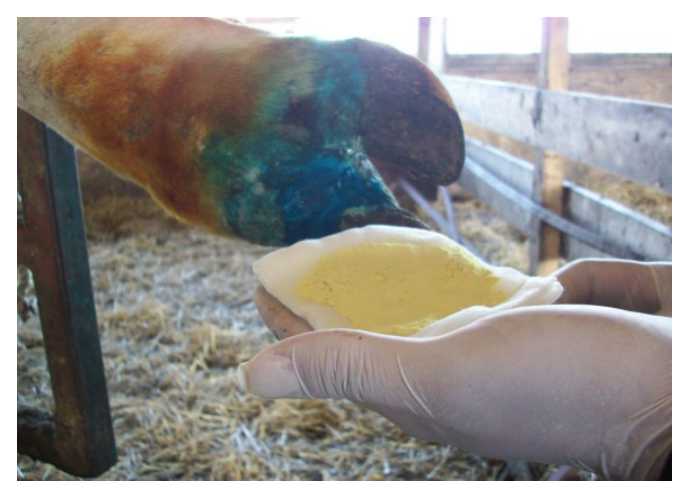

Fig. 4. Applying topical medication. 


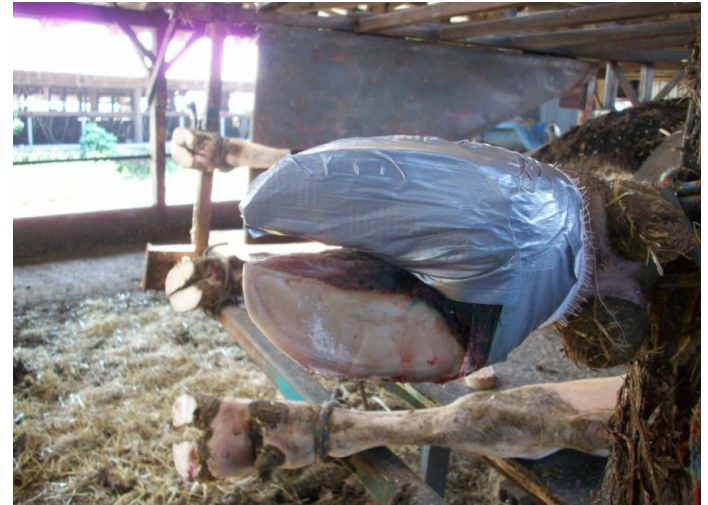

Fig. 5. Applying waterproof bandage.

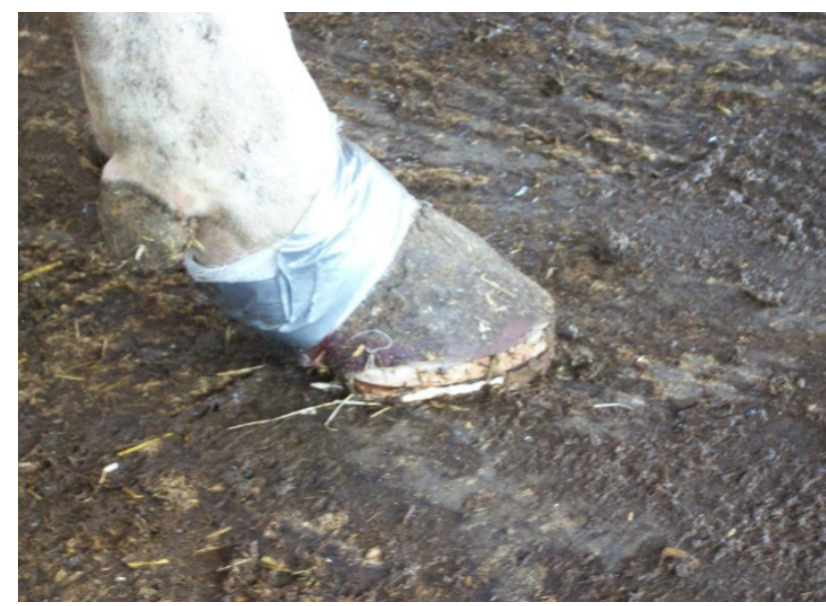

Fig. 7. Functional aspect of the block.

sec., and giving the adhesive, time to harden for approximatively 1 minute.

5. Loose horn was removed and all the hard edges was pared away, only healthy horn should be spared. After this the cow can be freed and the block is functional (Fig.7).

\section{RESULTS AND DISCUSSION}

At farm level from the total number of cows only $24 \%$ (43 cows) were lame, from this only on 13 cases with severe lesions was used orthopedic blocks. The rest of 30 cows were trimmed and treated since healing occurred.

Because the claw with severe lesions needs longer time for healing, the affected claw have been elevated by applying a foam or wooden block to relieve the weight bearing by the affected claw. Resting the affected hoof is highly efficient to promote healing and pain relief. This encourages the cow to move around, to feed as the pain is relieved.

The cows on which blocks were applied walk more easily then the cows that not benefit

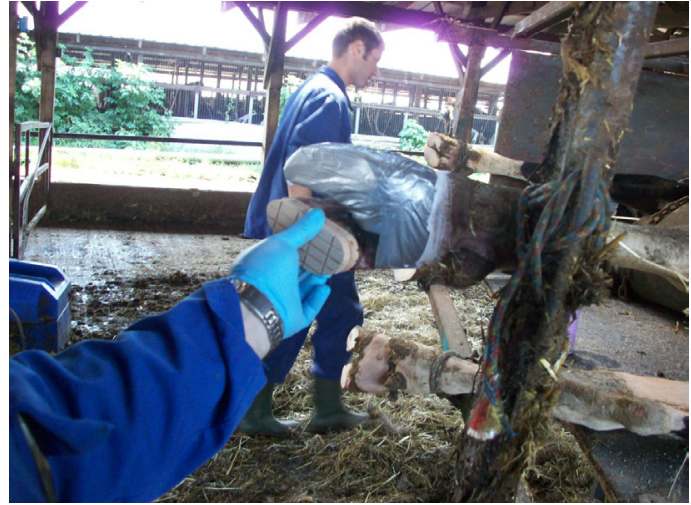

Fig. 6. Adjusting the orthopedic block.

from this treatment and on this cases lameness was observed compared with the ones on which blocks were applied. Usually the blocks wear down but on one cow after eight days the block fell down. The wooden blocks have a retention period between 23 and 39 days (Tab.1), the foam ones between 8 to 15 days (Tab. 2). Diseases treated with orthopedic blocks were Thin Soles (6 cases), Sole Ulcer (4 cases), White Line Disease (3 cases).

The bandages were changed every two days and topical medication was applied on every single case until healing. In average the time need for healing, depended on the severity of lesions, the most prolonged period was for a podal ulcer for which the time healing was extended to 30days.

The hoof blocks allows the cow to walk around freely, as the foam or wooden block wears down, the hoof disease is given time to heal. During a period of time, the blocks will worn down completely and the disease will be healed.

\section{CONCLUSION}

The hoof blocks allows the cow to walk around freely, as the foam or wooden block wears down, the hoof disease is given time to heal, relieving the lame claw from bearing weight.

Orthopedic blocks are comfortable, with no interference in the walking dynamic.

Hoof blocks are single use only and they stay on the claw from 1 to 6 weeks, during which they wear down or come off. Wooden blocks stayed on average 30 days, foam blocks stayed 12 days, allowing hoof healing process.

The use of hoof blocks reduces the economical loses caused by milk production drop, by decreasing reproductive performances and increased culling rate. 
Tab. 1. Retention period (BoviBond)

\begin{tabular}{cccc}
\hline Nr.Crt. & Case & Time days & Disease \\
\hline 1 & 1 & 27 & White line disease \\
\hline 2 & 2 & 39 & Thin sole \\
\hline 3 & 3 & 30 & Thin sole \\
\hline 4 & 4 & 25 & Sole ulcer \\
\hline 5 & 5 & 23 & Sole ulcer \\
\hline 6 & 6 & 30 & Sole ulcer \\
\hline
\end{tabular}

Tab. 2. Retention period (Walkease)

\begin{tabular}{cccc}
\hline Nr.Crt & Case & $\begin{array}{c}\text { Time } \\
\text { days }\end{array}$ & Disease \\
\hline 1 & 7 & 11 & Thin sole \\
\hline 2 & 8 & 15 & White line disease \\
\hline 3 & 9 & 13 & Sole ulcer \\
\hline 4 & 10 & 8 & Thin sole \\
\hline 5 & 11 & 15 & Thin sole \\
\hline 6 & 12 & 14 & White line disease \\
\hline 7 & 13 & 12 & Thin sole \\
\hline
\end{tabular}

The hoof blocks using are not time consuming with immediate positive effects.

\section{REFERENCES}

1. Beteg F, Muste A, Mates N, Krupaci A, (2010) Observation concerning functional trimming and hoof care in cows, Buletin USAMV,vol.67(2):32-37.

2. Booth CJ, Warnick LD, Grohn YT, Maizon DO, Guard CL, Janssen D, (2004) Effect of lameness on culling in dairy cows.J. Dairy Sci. 87:4115-4122.

3. Hernandez J, Shearer JK, Webb DW, (2001) Effect of lameness on the calving-to-conception interval in dairy cows. J. Am.Vet. Med. Assoc. 218:1611-1614.

4. Raven ET, Haalstra RT, Peterse DJ, (1989) Cattle footcare and claw trimming, Farming Press Ltd, Ipswich

5. Sogstad AM, Fjeldaas T, Osteras O, Forshell KP, (2005) Prevalence of claw lesions in Norwegian dairy cattle housed in tie stalls and free stalls. Prev. Vet. Med. 70:191209.

6. Warnick LD, Janssen D, Guard CL, Grohn YT, (2001) The effect of lameness on milk production in dairy cows. J. Dairy Sci. 84:1988-1997. 